Powell, Emma, Woodfield, Lorayne, A., Nevill, Alan, M., Powell, Alexander, J. and Myers, Tony D., 'We have to wait in a queue for our turn quite a bit': examining children's physical activity during primary physical education lessons, European Physical Education Review (25:4) pp. 929-948.

Copyright (C) [2019] (Copyright Holder). Reprinted by permission of SAGE Publications.

\title{
'We have to wait in a queue for our turn quite a bit': examining children's physical activity during primary physical education lessons
}

\author{
Emma Powell \\ Faculty of Education, Newman University Birmingham, UK \\ Lorayne A Woodfield \\ Faculty of Arts, Society and Professional Studies, Newman University Birmingham, UK \\ Alan M Nevill \\ Faculty of Education, Health and Wellbeing, University of Wolverhampton, UK \\ Alexander J Powell \\ Faculty of Arts, Society and Professional Studies, Newman University Birmingham, UK \\ Tony D Myers \\ Faculty of Arts, Society and Professional Studies, Newman University Birmingham, UK
}

\section{Abstract}

The overall purpose of this study was to examine children's physical activity (PA) during primary physical education (PE). This was achieved through the following two research objectives: 1) to measure children's PA, lesson context and teacher promotion of PA during PE lessons; and 2) to explore teachers' and children's perspectives on PA levels during PE lessons. Evidence suggests that children's PA during PE is below recommended levels and further research is required to understand the reasons why. Through a mixed method design, 138 children were observed using the System for Observing Fitness and Instruction Time (SOFIT), 80 children participated in group 
interviews, and 13 teachers were interviewed, across three primary schools in England. Findings indicated that the mean percentage of lesson time allocated to moderate to vigorous PA (MVPA) was $42.4 \%$ and the average lesson length was 35.3 minutes. Qualitative themes identified were: 'knowledge and beliefs', 'teacher pedagogy', and 'teacher development'. The findings indicate that a change in perspective is needed, which includes a focus on PA during primary PE lessons. Intervention work is required that targets teachers' knowledge and beliefs towards PE along with the development of effective teaching strategies. However, this needs to be grounded in an ecological approach which will allow the researchers and schools to target the various levels of influence. It is strongly recommended that interventions are grounded in behaviour change theory, as this study indicates that sharing knowledge of pedagogical strategies to increase children's MVPA does not necessarily produce changes in teachers' behaviours.

\section{Keywords}

Children, physical activity, physical education, mixed methods

\section{Introduction}

The Association for Physical Education (AfPE) specified that physical education (PE) should involve the key concepts of 'learning to move' and 'moving to learn', with the context of learning being focused on physical activity (PA) through a range of activities and experiences (AfPE, 2015). Additionally, the National Curriculum programme of study for primary PE in England aims to ensure that all children 'are physically active for sustained periods of time' (Department for Education [DfE], 2013a). Physical education in the primary curriculum in England is a unique subject as it involves learning through 
the physical, with a target of $50-80 \%$ moderate to vigorous PA (MVPA) being recommended (AfPE, 2015). However, reviews of children's MVPA in primary PE have indicated that levels fall below this. For instance, Fairclough and Stratton (2006) highlighted that children were only engaged in MVPA for an average of $34.2 \%$ of lesson time, and the more recent meta-analysis conducted by Hollis et al. (2016) reported an average of $44.8 \%$. Even though this demonstrates a positive increase of $10 \%$ MVPA between the reviews, Hollis et al.'s (2016) reported figure still falls below AfPE's (2015) recommendations of $>50 \%$ MVPA. However, it is important to note that Hollis et al.'s (2016) review did also evidence a range of MVPA levels (11.4-88.5\%), thus indicating that achieving above the recommended $>50 \%$ is possible.

As acknowledged by Parker et al. (2017), PA is not the sole purpose of primary PE. However, if children are only active for $11.4 \%$ of a lesson (Hollis et al., 2016) then the quality of any physical learning taking place during that lesson can be questioned. Examples of skills that would engage children in MVPA during PE include: locomotive movements, holding balances such as the plank in gymnastics, jumping during the set shot in basketball etc. (McKenzie, 2015). It has been recommended that future intervention work is needed to address children's low levels of MVPA during primary PE lessons (Hollis et al., 2016). Furthermore, there is a paucity of intervention work in England that aims to increase children's MVPA levels in PE lessons through teaching strategy approaches rather than purely fitness based interventions (Lonsdale et al., 2013). Therefore, examining the reasons why some teachers are not achieving the target of $>50 \%$ MVPA would provide essential information in the design of such interventions in England. 
Low MVPA levels in primary PE lessons could be a result of pedagogical characteristics often observed in a typical PE lesson (Fairclough and Stratton, 2006). For instance, children are frequently stopped to receive instructions, to observe demonstrations and to be involved in the organisation of equipment and groupings (Fairclough and Stratton, 2006). Schools have also reported a number of barriers to increasing children's MVPA levels during PE lessons such as: policy and infrastructure (Barroso et al., 2005), low teacher confidence, and limited subject knowledge in teaching active PE lessons (Tsangaridou, 2012). Taking into consideration these barriers it is not surprising that some practitioners are struggling to achieve $>50 \%$ MVPA. Further contributing factors may be potential memes that are said to exist within primary PE in the UK (Ward and Griggs, 2017). This can be considered as a cyclic reproduction of previous practice, which would help to explain the continuous low levels of MVPA in primary PE lessons. For instance, Ward and Griggs (2017) identified 'nowhere important' as a potential meme within primary PE. This meme places PE as a less important subject than English and Mathematics, and which is often taught with limited facilities and equipment (Ward and Griggs, 2017), all of which, could potentially impact upon children's MVPA during PE lessons.

The measurement of children's MVPA levels during primary PE lessons provides an indication of whether lessons are active and more specifically if teachers are achieving the recommended $>50 \%$ in their lessons. This is especially important as the systematic reviews previously reported (Fairclough and Stratton, 2006; Hollis et al. 2016) suggest that MVPA in many PE lessons falls well below the $50 \%$ threshold. However, in order to examine the reasons behind these figures it would be useful to 
explore teachers' and children's perspectives of MVPA levels in PE lessons alongside the quantitative measures. Thus, using a mixed method design would help to explore reasons behind low MVPA levels during primary PE lessons, an approach previously advocated (Castelli et al., 2014). Furthermore, a number of researchers over the past decade have drawn upon a range of qualitative methods in order to explore children's perceptions of PE (Coulter and Woods, 2011; Dyson, 2006; Parker et al., 2017) and it is important to continue to build upon this. Accordingly, an additional contribution of this paper is the mixed method design, which could provide further insights into the problem of children's low MVPA levels during primary PE lessons.

The application of an ecological lens could also assist with understanding the various factors that may impact upon children's low levels of MVPA during primary PE lessons. An ecological approach has been advocated to develop our understanding of primary $\mathrm{PE}$, as it places a focus on the interaction between the various levels of influence in a primary school setting (Carse et al., 2017; Safdie et al., 2014). When working in this framework, complex interactions are taken into account between several layers including: the intrapersonal, the interpersonal, institutional, community, and public policy (McLeroy et al., 1988). In the case of primary PE, the multiple layers of influence would involve: knowledge, attitudes and behaviour of the individual child or teacher (intrapersonal); formal and informal social networks such as peers (interpersonal); organisational characteristics, formal and informal rules which can include the physical environment, equipment and school policy (institutional); relationships with other organisations including school partnerships and links with sports clubs and professional bodies (community); and political, sporting, and health agendas, for example the UK's 
PE and Sport Premium Funding (DfE, 2017) (public policy). It is thought that gaining a thorough understanding of these various levels of influence could assist in understanding teachers' and children's behaviours during primary PE lessons (Carse et al., 2017). This, in turn, will provide insights into the reasons behind children's low levels of MVPA during primary PE lessons. Thus, in this present study, in order to examine children's PA during PE lessons, an ecological lens was applied to address the following individual research objectives: 1) to measure children's PA, lesson context and teacher promotion of PA during PE lessons; and 2) to explore teachers' and children's perspectives on PA levels during PE lessons.

\section{Methods}

\section{Participants and settings}

A convenience sample of 138 children (68 boys and 70 girls) across school years three and four (aged seven to nine years) in three primary schools in the West Midlands, England were selected to participate in the quantitative aspect of the study. The convenience sample was selected through existing relationships with the three primary schools. From this convenience sample, purposive sampling was then applied to select 80 children (42 boys and 38 girls) for semi-structured group interviews ( $n=10)$. The inclusion criteria for purposive sampling were children who: speak English, represent diversity in activity levels and were comfortable speaking in group situations. In addition, 13 teachers (three males and 10 females) were purposefully selected and individually interviewed, as they were the class teachers of the children participating in the study and therefore would be observed teaching PE; their teaching experience ranged from two to 15 years. In the quantitative phase, 23 pre-determined PE lessons were 
observed (Table 1) (ranging from seven to nine lessons in each school), totalling 807 minutes of observed lesson time and 2421 observed intervals. The lessons took place in standard primary school halls or playgrounds typical of English primary schools. Lessons in which swimming took place were observed in a small sectioned off area of a public 20m swimming pool.

The study was approved by the Research Ethics Committee at the lead researcher's institution and written informed consent was obtained from the head teachers of each school, the observed teachers and the children's legal guardians. Verbal assent was also gained from all the children who took part in the study. All researchers who visited the schools were experienced in working with children in a school setting. Both the quantitative and qualitative data were collected consecutively in each school between the months of April 2014 and December 2015 (e.g. school one: April and May; school two: June and July; and school three: November and December). Four researchers collected quantitative data in each school and two of these researchers also collected qualitative data in each school.

\section{Quantitative data collection: direct observation}

The System for Observing Fitness and Instruction Time (SOFIT) (McKenzie, 2015) was employed. SOFIT is a comprehensive tool for assessing PE classes, as it allows for the simultaneous collection of data across the three variables of: children's activity levels, lesson context and teacher interaction (PA promotion). Six children were observed during each PE lesson on a rotational basis. Therefore, as the SOFIT tool is a class level measure it provides a mean (\%) total for the six observed children. The observation period began when $51 \%$ of the class arrived in the working area and the 
observation ended once $51 \%$ of the class had left the observation area (McKenzie, 2015). To maintain the consistency of the observations a pacer was used on an MP3 player, from which the researchers were prompted to observe for a 10 second period and then record the observed behaviour for a 10 second period. Full details of the SOFIT protocols can be found elsewhere (McKenzie, 2015). To reduce observer reactivity, and to assist with children's safety, researchers positioned themselves on the edge of the working area during all lesson observations.

\section{SOFIT validity, reliability and observer training}

Systematic observation is viable to use when researchers are working within an ecological model, as it develops the researcher's understanding of PA in relation to both the physical and social influences (McKenzie, 2002). Direct observation has a high internal validity for measuring PA and has been used as a criterion for validating other PA measures (McClain et al., 2008). Data were collected by four trained observers and intra and inter-observer agreement criterion was set before data were collected. An infield inter-observer reliability check took place between two of the observers, in which the chosen observers were randomly selected. In accordance with the SOFIT manual (McKenzie, 2015), all intra, inter, and infield inter-observer reliability checks were over $80 \%$ in each of the SOFIT categories. Furthermore, the infield reliability check took place in one out of 23 lessons (equating to $4.3 \%$ of observed lessons).

\section{Qualitative data collection: interviews}

The children's group interviews and the individual teacher interviews were conducted to explore their perspectives on PA levels during PE lessons. The nature of a group 
interview enables child participants to feel more relaxed and it has been suggested that the discourse may be richer than in one-to-one situations (Flewitt, 2014). Therefore, 10 group interviews were conducted consisting of eight children in each group (Menter et al., 2011). For the individual teacher interviews, a semi-structured approach was employed which offered greater flexibility for the researchers to follow up emerging lines of enquiry (Flewitt, 2014). Both the children's and teachers' interview questions were structured according to the Social Ecological Model for Health Promotion (McLeroy et al., 1988), and pilot interviews took place prior to data collection. Following the pilot interviews, prompt questions were added to the interview questions to help provide further clarification. Examples of the children's group interview questions included: 'What do you think I mean by the word active?', 'How active do you think you are?', 'How active do you think you are in your PE lessons?', 'Why do you think you are active or not active during PE?', and 'What do your teachers do during your PE lessons?'. Examples of the teacher interview questions included: 'How would you describe PE in your school?', 'How confident do you feel teaching PE?', 'How active do you think the children are in PE lessons?', and 'Are there any facilitators or barriers to children being active during PE lessons?' All interviews lasted between 25 - 40 minutes and the discussions were recorded via a Dictaphone.

\section{Quantitative data analysis}


The quantitative data were analysed using the Statistical Package for the Social Sciences v.23, with the alpha level being set at $P<.05$. The mean, range and standard deviation of the SOFIT variables were calculated. Due to the ordinal data being treated as interval data and converted to percentages, the data were considered as continuous for the purpose of analysis. Pearson product-moment correlations were then conducted to present preliminary examination of the association between SOFIT variables. To provide further analysis of the data, multiple regression was applied to the children's PA behaviours as the dependent variables. Specifically, each of the SOFIT activity variables (lying, sitting, standing, walking, MVPA and Vigorous Physical Activity [VPA]) were the outcome (dependent) variables across six regression models, with each model including the predictor (independent) variables of: 'management', 'knowledge', 'fitness', 'skills', 'games', 'other', 'in class promotion of PA', and the confounding variables of 'school' and 'age'.

As the SOFIT tool produces a range of predictor variables, the backwards selection enabled the model to be refined sufficiently and thus was the most efficient way of identifying predictor variables. In this process, non-statistically significant variables that were least strongly associated with the outcome variable were removed. Variables were retained if they were statistically significant predictors of the outcome variables. As the SOFIT tool is a class level measure, each PE lesson observed was treated as a 'case' in the regression analysis (i.e. a case = one observed lesson), with 23 cases (i.e. lessons) being considered as an adequate sample size for the number of predictor variables applied to each linear regression model (Austin and Steyerberg, 2015). 
To enable trustworthy conclusions from the data, the following assumptions for multiple regression were checked for each model: 1 . Homoscedasticity of errors through plotting standardised residuals against the predicted values of $Y ; 2$. Multicollinearity through the presence of correlations between the predictor variables; 3. Outliers from the application of Cook's distance diagnostic; and 4. Linearity of the predictor and outcomes variables (Williams et al., 2013). As the SOFIT tool is designed as a class level measure (i.e. observations are made on six children at 20 second intervals which are then calculated into lesson totals), in order to examine sex differences in children's activity behaviours, the data were aggregated separately for boys and girls. A two-way ANOVA was then used to determine any main effects for 'sex' and 'school' on the activity categories of MVPA, VPA, walking, standing, sitting and lying. The statistical assumptions for a factorial analysis of variance (ANOVA) were adhered to which included: using Levene's test to check for equality of variances of all data points of the dependent variable; and ensuring normality of residuals through the use of a histogram (Cohen et al., 2011).

\section{Qualitative data analysis}

\section{Interpretative Phenomenological Analysis}

All qualitative data were analysed using Interpretive Phenomenological Analysis (IPA) (Smith, 1997). IPA is an approach which acknowledges that the results will always be influenced by the researcher's views and interpretations of the participants' experience, thus, such an approach accepts that it is not possible to gain direct access to the participants' world view (Willig, 2001). This element is referred to as the hermeneutic nature of an IPA approach. Hermeneutics in IPA is focused on interpreting meanings in 
which the researcher interprets the participants' interpretations; this is referred to as double hermeneutic. Thus, the main objective of IPA is to interpret meanings rather than measure the frequency of any given response. IPA is also grounded in the philosophical areas of phenomenology and idiography (Smith et al., 2009). The phenomenological element is the central focus on the human experience, which places the participant as the 'expert' and it is the meanings that the participants attach to their experiences that are important to the researcher (Smith et al., 2009). The idiographic component of IPA involves the researcher's committed detailed examination of each transcript, which involves verbatim transcription and reading the transcript several times to enable immersion into the participant's world (Smith et al., 2009).

A systematic analysis of each transcript took place in which the first step involved reading and re-reading the transcripts and at this stage of the analysis, initial notes were recorded. In the second step, exploratory comments were produced and broken down into: descriptive (e.g. a description of the content), linguistic (e.g. specific use of language) and conceptual (e.g. an interrogation and interpretation) (Smith et al., 2009). The third step led to the development of emergent themes in which the focus was placed upon reducing the large amount of data to discrete phrases representing the large data set. This entailed breaking up the narrative flow of the interviews and fragmenting the hermeneutic cycle. The next stage of the analysis progressed onto the abstraction of themes. At this point the themes were drawn together and a structure was produced providing organisation to the analysis. This systematic process was repeated for each interview, which was followed by a comparison of themes across transcripts to produce 10 sub-themes that represented the teachers' and children's perceptions and 
experiences of the phenomenon. The themes were then clustered according to layers of the Social Ecological Model (SEM) (McLeroy et al., 1988), from which three main categories/themes were produced (Figure 1).

\section{Trustworthiness}

The trustworthiness of the qualitative data was increased through the application of the following four concepts: credibility, transferability, dependability and confirmability (Shenton, 2004). The credibility of the qualitative data set was increased through the application of member checking during the interview process and the researchers discussing their assumptions with critical colleagues post interview. Moreover, the credibility of the data was increased due to the systematic approach adopted and the verbatim extracts included in the results and discussion, which provides the reader with the opportunity to check the interpretations made. The transferability of the data is evident through the detailed contextual information provided regarding the environment under study and the clear communication of the boundaries of the study. The dependability of the research was increased due to the thorough description of the research design and the methods employed. Finally, the confirmability of the study is apparent through the bracketing of initial ideas which took place by the researchers noting down any predispositions regarding activity levels in primary PE lessons, to ensure that the researchers were fully open to the researcher encounter.

\section{Results}

SOFIT 
Table 2 presents the means, standard deviations and range for the number of minutes and percentage of lesson time allocated to children's PA, lesson context and teacher interaction (PA promotion). From the lessons observed the mean average length of a lesson was 35.3 minutes, with lessons ranging from 24 to 52 minutes (Table 2). The mean proportion of time children spent in MVPA during PE lessons was $42.4 \%$, equating to 15 minutes of lesson time and ranging from 22 to $62.5 \%$. Out of the 23 lessons observed, seven lessons met the recommended $>50 \%$ MVPA. Children spent a mean of $34 \%$ of lesson time standing and $21.7 \%$ sitting. An average of $17 \%$ was allocated to vigorous activity, with a mean value of 5.8 minutes. In terms of lesson context, the majority of class time was spent engaged in the SOFIT category of 'games activities' (i.e. application of skills, for instance creating a sequence in gymnastics or a game of basketball) (29.2\%) followed by 'knowledge' (20.7\%). The least amount of class time was allocated to 'other' (4.4\%), which included demonstrations of children's work. In relation to teacher promotion of PA, $16.1 \%$ of class time was spent promoting in class $\mathrm{PA}, 0 \%$ was allocated to promoting out of class PA, and $82.9 \%$ was allocated to no promotion of PA.

A positive correlation was found between sitting and the lesson context of 'knowledge' $\left(r(23)=.70, p=<.01, r^{2}=.48,95 \% \mathrm{Cl}[.398, .861]\right)$ (Table 3). Further results from applying multiple regression analysis (using children's activity behaviours as the outcome variables) indicated that the lesson contexts of 'management', 'fitness', 'skills' and 'games' were negative predictors of children's sitting behaviour but were positive predictors of children's MVPA during PE lessons (Table 4). Furthermore, the lesson contexts of 'knowledge' and 'other', along with 'teachers in class promotion of PA' and 
the confounding variable of 'school' were negative predictors of children engaging in moderate activity (walking). In addition, the lesson context of 'other' and the confounding variable of age (year group) were negative predictors of children's $\%$ time spent standing during PE lessons. The two-way ANOVA results revealed a nonstatistically significant interaction effect between 'sex' and 'school' across all SOFIT activity categories. Also, no statistically significant main effects for 'sex' were revealed for VPA, MVPA, walking, standing, sitting and lying during PE lessons. Although there were no statistically significant differences across the three schools in relation to \%MPVA (school one $=42.5 \%$, school two $=42.2 \%$, school three $=42.5 \%$ ), the ANOVA results revealed significant main effects of 'school' on children's \%VPA $F(2,37)=3.76$, $P=.033, \eta_{p}^{2}=.17$, and $\%$ MPA (walking), $F(2,37)=5.30, P=.009, \eta_{p}^{2}=.22$, revealing that school 3 spent a larger proportion of their time engaged in VPA (22.9\%) during PE lessons compared to schools one (12.3\%) and two (14.2\%). However, schools one $(30.2 \%)$ and two $(28.1 \%)$ spent a larger proportion of their time engaged in MPA than school three (19.7\%).

\section{Interviews}

From analysing the interview data, 10 sub-themes were identified. These sub-themes were then clustered according to layers of an ecological model (McLeroy et al., 1988), from which, three main categories/themes were produced: knowledge and beliefs, teacher pedagogy, and staff development (Figure 1).

\section{Theme 1: Knowledge and beliefs (intrapersonal layer)}




\section{Teachers' low confidence (teachers' sub-theme)}

The majority of teachers expressed that their confidence levels were low in one or more areas of primary PE. There was also an uncertainty in their abilities, staff did not know whether they were effective or not at teaching PE and also some teachers feared that the children would know more than them. For instance:

It is the one that I worry about the most and I feel less confident doing it... it is the one that makes me panic.

I don't think anybody within the school is confident, even the people that have gone on courses.

I still don't know whether I am doing the right thing by questioning myself all the time.

I was quite daunted by the prospect of it when I first came and I had a year five class so obviously it's a bit scary when they are older because I felt like they probably know more than me.

\section{Holistic approach to primary PE (teachers' sub-theme)}

The teachers expressed a holistic view towards the teaching of primary PE, highlighting the mixture of aims within the subject. For instance:

It's a very sociable thing sport and you know, learning to take turns.

You have to teach them it's not just about winning, it's about organisation and there are lots of skills that go with it.

The majority of teachers believed that PE should be active as expressed in the following examples: 
Definitely over $50 \%$ (activity levels) is right, otherwise there is no point in doing PE really is there, if they are all stood still watching.

I think that it is important that they are active because it is a PE lesson and if we were only doing maths for say $40 \%$ of a maths lesson then that wouldn't be good enough so I suppose it is the same thing in PE.

\section{Primary PE is a low priority subject (teachers' sub-theme)}

One of the main barriers discussed by the teachers was the priority and time given to mathematics and English which impacted upon the time they had available for PE. In some schools PE was described as a low priority subject area, as highlighted in the following quotes from some of the teachers:

We meticulously plan all of our maths and English because we have to and they are the most important and we know that, and the afternoon lessons can tend to be a bit ad hoc, but you know, that's just what primary school teachers are like, master of nothing.

You kind of focus so much on maths and English that you sort of rush through and sometimes I don't feel 100\% prepared when I am teaching PE and that's quite daunting.

\section{Theme 2: Teacher pedagogy (interpersonal layer)}

\section{Teacher talk and demonstration time (children's sub-theme)}

The children discussed the impact of teacher talk and demonstration time on their learning, as illustrated in the following quote:

Sometimes the teacher is demonstrating and they do it for ages... and then I say to myself, you are taking for ages, if you don't realise that and you are getting me bored so I have to try and do something to make me not bored. 
The children also appeared to have a good understanding of how they could be more active in their PE lessons:

So maybe the teacher could demonstrate quickly at the start and then just let us do it, so do it at the start and then we have the rest of the PE lesson to do what the teacher has demonstrated.

\section{Teacher talk and not stopping the whole class (teachers' sub-theme)}

Teachers also discussed their awareness of different elements of teaching that can impact upon activity levels during PE, such as demonstration time, for example:

There is nothing worse than watching a PE lesson and the teacher is standing and doing all the talking and the children aren't doing anything, they are just sitting there.

I think it's a lot like getting them going as soon as possible and then going around and talking to them in their groups rather than getting the whole class to stop.

\section{We have to wait in a queue for our turn quite a bit (children's sub- theme)}

In one of the schools the children reflected upon the limited space and organisation during their PE lessons and how this often resulted in them queuing in large groups waiting for their turn to practise their skills, for instance:

For indoor PE you have to watch and see what she is trying to show us and then you have to give it a go and you have to wait in a queue for like four people to have their turn. 
In gymnastics we are not very active because the teacher demonstrates it but we only like jump off and do rolls, that is all we do...we have to wait in a queue for our turn quite a bit.

The children commented on the organisation of groups in PE and how this affected their learning, for example:

I think maybe for PE if everyone had their own bit of playground or hall space, then it wouldn't take as long as everyone could just do it over and over again and they would get more practice and they would know what they are doing and become more confident with it.

Normally we are in a team and we have to wait for the other five people in front of us to have a go but if you are on your own you can do it quicker because you are not waiting for anyone else.

\section{Sitting out for misbehaving (children's sub-theme)}

In some of the interviews, children described that if they misbehaved during their PE lesson they were asked to sit out, and sometimes this was for the remainder of the PE lesson. As expressed in the following quotes:

Sometimes when you are silly you are told to sit on the orange spot or the bench.

If you sit on the orange square more than once then you have to sit on the orange square for the rest of the PE lesson.

You have two warnings, then you have to sit there and watch people, then you miss your whole PE lesson. 


\section{Theme 3: Teacher development (institutional, community and public policy layers)}

\section{Support networks (teachers' sub-theme)}

In one of the schools, they had developed a range of supportive networks. There was effective leadership in PE across all three schools which was often developed through a 'PE team' and teachers frequently discussed the professional dialogue they engaged in, for instance:

I have other colleagues who are particularly good at PE and they have the specialist PE knowledge...there are plenty of people to speak to.

\section{Staff training (teachers' sub-theme)}

A range of staff development opportunities were available across the three schools and particularly so in one of the schools, as the teachers stated that the training had developed their pedagogical knowledge. They reported finding it particularly useful observing the practice of others, as highlighted by one of the teachers:

He is really helpful (PE co-ordinator). For instance if you say I don't know what to do he will come and help you and he has team taught with me a couple of times.

\section{Outside agencies (teachers' sub-theme)}

All three schools had developed links with outside sporting agencies. In one of the schools they discussed their use of a coaching company to support teachers with their knowledge and understanding of PE as highlighted in the following quote: 
I think as a teacher sometimes it is subject knowledge... and I think the PE team here has worked on that, you know, has put things in place. They organise instructors to come in and help us.

\section{Discussion}

The study highlights that children accumulated a mean average of 15 minutes MVPA (equivalent to $42.4 \%$ of lesson time) during PE lessons. These results are similar to the recent meta-analysis results (44.8\%) of Hollis et al. (2016), but still fall below the recommended $50-80 \%$ (AfPE, 2015) MVPA during PE lessons. Furthermore, the study's findings also indicated that the average length of a PE lesson in which children were in the working area (e.g. school hall, field, swimming pool) was 35.3 minutes, which falls short of the recommended two hours per week of PE in England (AfPE, 2015). Therefore, of the typical allocated one hour of time for a PE lesson, this study's results indicate that 35.3 minutes of this time is being spent in the working area (e.g. school hall etc.), with children being engaged in MVPA for only 15 minutes. Hence, it is important to understand the factors that can influence children's PA levels during primary PE lessons. From the analysis of both the quantitative and qualitative data, the factors that can impact upon children's MVPA during PE will be discussed according to the three main categories of: teacher knowledge and beliefs, teacher pedagogy, and teacher development. All of which also align with layers from the SEM (McLeroy et al., 1988).

\section{'Knowledge and beliefs' (intrapersonal layer)}

Across all three schools, teachers' low confidence and subject knowledge were barriers to children's MVPA levels, as highlighted in the qualitative data. Even if teachers felt confident in some areas of the PE curriculum, they often expressed a lack of confidence 
in other sports/areas of the curriculum. This supports previous research which has identified teachers having low confidence to teach primary PE (Tsangaridou, 2012). Furthermore, it is a similar finding to that of Dyson et al. (2017), who noted that even if a teacher viewed themselves as being confident in teaching PE, often they are only confident teaching a small selection of activity areas. The teachers' lack of confidence may be linked to other barriers identified in the interview data such as the sub-theme of 'PE a low priority subject' which often resulted in teachers having limited time available to plan for their PE lessons. This finding links to other research which has emphasised PE being viewed as less important compared to subjects such as English and mathematics; as identified by Ward and Griggs (2017) it is seen as a subject that takes children and schools 'nowhere important'. If teachers perceive PE as being a low priority subject and, as a result, are not prioritising their time to plan for PE, then it is likely that they will replicate previous PE lessons in which children's MVPA is often low.

Low MVPA levels may also link to teachers' perspectives on the purpose of primary PE. As highlighted in the teacher interview data, the teachers expressed the variety of aims in the subject area. For instance, they viewed it as being a social activity in which the teaching of moral values was integrated, along with the development of physical skills. However, the teachers also acknowledged the importance of the children being active during their PE lessons, stating that if children are not active in PE then there would be no point in teaching the lesson, although this view of the importance of being active in PE did not reflect the SOFIT findings in which children did not achieve over $50 \%$ MVPA. The status of primary PE in England still remains an issue (Carse et al., 2017), and this was evident from the teacher interview data, where PE was seen as 
a low priority subject, with little planning time and mixed views on the purpose of the subject. Furthermore, if teachers are unclear of the focus of primary PE then even though they may express the need for children to be active during primary PE lessons, in reality this may not happen, as was evidenced in the SOFIT data. As stated by Carse et al. (2017), if primary PE is to survive as a viable subject there must be a change in perspectives. In the authors' view, this change in perspective must include a focus on PA with children achieving at least $50 \%$ MVPA to develop their physical skills. If primary PE was to lose the PA element then the viability of the subject could be questionable. Additionally, a change in perspective is needed in relation to the allocated time for PE lessons, as the study highlights that the length of PE lessons was below the recommended two hours per week (AfPE, 2015).

\section{'Teacher pedagogy' (interpersonal layer)}

When considering teacher pedagogy specifically related to children's MVPA during primary PE lessons, the SOFIT results indicated that the lesson contexts of 'knowledge' (i.e. teacher transfer of knowledge through dialogue and demonstration time) and 'other' (i.e. children demonstrating work) were identified as barriers to children engaging in moderate PA. Transfer of knowledge (dialogue) and providing demonstrations are important aspects of high quality teaching and learning as illustrated in England's Teachers' Standards (DfE, 2013b). However, what needs to be considered is how teachers can communicate effectively without talking for long periods of time, which can impact upon children's MVPA in PE and their motivation to learn. As identified from the children's interview sub-theme 'teacher talk and demonstration time', the children became bored and lost interest during these aspects of PE lessons. The children 
reported that the teachers would talk 'for ages', and although younger children can have difficulties with the concept of time this qualitative finding was supported by the SOFIT data in which $20.7 \%$ of the lesson was spent in the category of 'knowledge'. The children also described how they often wait in queues during their PE lessons, and if they misbehave are asked to sit out and not take part in activities. All of which will impact upon children's MVPA during their PE lessons.

Frequently stopping the children to listen to instructions and view demonstrations has been reported as typical teacher behaviour in primary PE lessons (Fairclough and Stratton, 2006; Ofsted, 2013) and was also evident through this research. Thus, this pedagogical characteristic of PE could be considered as a cyclic reproduction of previous practice. As highlighted by Ward and Gavin (2017) potential memes exist within primary PE with elements of certain practices being passed on from one teacher to another. Therefore, there needs to be a change in perspective towards pedagogical approaches commonly used in primary PE lessons (for example, frequently stopping the children to listen to instructions) as current practices could be viewed as ineffective due to low MVPA levels and children's demotivation to learn. Hence, teaching strategies such as only stopping small groups to give feedback rather than the whole class and reducing the amount of time teachers give instructions/feedback for must be promoted to help address the cyclic reproduction of current pedagogical practice.

\section{'Teacher development' (institutional, community and public policy layers)}

The interview sub-themes of 'networks of support', 'staff training' and 'outside agencies' all provided insights into the advantages of establishing social networks in schools in 
order to support teachers in their knowledge of and confidence in teaching primary PE. Often this was developed through professional dialogue with other staff, one to one staff training from the use of coaches working along-side teachers and attending PE courses. From the teacher interview data it emerged that some teachers were developing their knowledge of how to increase children's MVPA levels during primary PE lessons, as they described strategies that would enable them to do this. However, the SOFIT data indicated that they were not implementing these strategies during PE lessons. This links to research that has been undertaken in relation to teacher development and communities of practice (Patton et al., 2015), which has emphasised that thinking needs to shift when considering the development of teachers. For instance, the current paper and previous research (Fairclough and Stratton, 2006; Hollis et al. 2016) indicate that children's MVPA levels in primary PE have been consistently below the recommended $>50 \%$, with pedagogical strategies being frequently suggested to increase children's MVPA (i.e. reducing teacher talk, eliminating queues etc). Thus, the pure suggestion and dissemination of pedagogical strategies to teachers does not appear to have an impact.

As Patton et al. (2015) advocate, teacher development should not be a 'neat and tidy dissemination model'; it is often a messy process that includes a range of strategies and organisational arrangements. Therefore, the authors argue that the application of a social ecological lens could assist with this, as the application of this lens to the data analysis enabled the identification of social ecological clusters from the interview subthemes. This assisted in revealing the various layers of impact upon children's MVPA levels during primary PE and the development of the three main categories (knowledge 
and beliefs, teacher pedagogy, teacher development) which could be targeted in future intervention strategies. Consequently, the recommendations as a result of this research would be to design interventions that address the following concepts:

- 'knowledge and beliefs' through creating a shared aim of teaching primary PE lessons with $>50 \%$ MVPA.

- 'pedagogy' through the creation/dissemination of pedagogical strategies to increase children's MVPA during PE such as reducing teacher talk, eliminating queues, only stopping small groups rather than the whole class etc.

- 'teacher development' through the consideration of behaviour change theory to motivate individuals and communities of practice to change and sustain their behaviour.

Furthermore, although the UK's PE and Sport Premium Funding (DfE, 2017) was not a focus of this study, it could be used to support the development of these interventions.

\section{Limitations}

A limitation of the study would be the relatively small sample size of three primary schools in one regional area of England. Further limitations were that the lesson selection did not take place periodically as is advised in the SOFIT manual (McKenzie, 2015) and potential reactivity of both the teachers' and children's behaviour from the presence of the researcher observing the lesson.

\section{Conclusion}

The overall purpose of this study was to examine children's PA during primary PE lessons. The study evidenced that children were only engaging in MVPA for 15 minutes 
(42.4\%) per lesson, which is below the recommended 50-80\% MVPA (AfPE, 2015). The qualitative data highlighted a number of pedagogical strategies that teachers employed which impacted upon children's MVPA, such as too much teacher talk and demonstration time (to the extent that children became bored and lost interest) and children waiting for their turn to practise a skill. While some of the teachers were aware of strategies which they could employ to increase children's MVPA during PE lessons, the SOFIT data suggests that these strategies were not being put into practice. This may link to the teachers' confusion over the main aims of primary PE. Thus, a change in perspective is recommended which includes a focus on PA during primary PE lessons in which children will achieve at least 50\% MVPA. Additionally, further research is recommended on the allotted time children spend in the working area during their PE lessons (i.e. school hall, field, swimming pool etc) as this study indicated that PE lessons were an average of 35.3 minutes, which falls short of the recommended two hours per week (AfPE, 2015) in England. Accordingly, future intervention work is recommended that targets teachers' knowledge of and beliefs towards PE along with the development of effective teaching strategies. However, this needs to be grounded in an ecological approach which will allow the researchers/schools to target the various levels of influence. A strong recommendation is that interventions are grounded in behaviour change theory, as this study indicates that sharing knowledge of pedagogical strategies to increase children's MVPA does not necessarily produce changes in teachers' behaviours. Furthermore, it is advised that the UK's PE and Sport Premium Funding (DfE, 2017) could be used to support the development of these interventions in England. 


\section{Acknowledgements}

With sincere thanks to all children and schools who took part in the study.

\section{Funding Source}

There were no financial interests related to this research.

\section{References}

Association for Physical Education (2015) Health Position paper. Physical Education Matters, 10(3): 87-90

Austin PC and Steyerberg EW (2015) The number of subjects per variable required in linear regression analyzes. Journal of clinical epidemiology, 68(6): 627-636.

Barroso CS, McCullum-Gomez C, Hoelscher DM, Kelder SH and Murray NG (2005) Self-reported barriers to quality physical education by physical education specialists in Texas. Journal of School Health, 75(8): 313-319.

Carse N, Jess M and Keay J (2017) Primary physical education: Shifting perspectives to move forwards. European Physical Education Review, p.1356336X16688598.

Castelli DM, Carson RL and Hodeges Kulinna P (2014) Special issues: Comprehensive school physical activity programmes. Journal of Teaching in Physical Education, 33: 435-439.

Cohen L Manion L and Morrison K (2011) Research methods in education (7 $\left.7^{\text {th }} \mathrm{ed}\right)$. London: Routledge.

Coulter M and Woods CB (2011) An exploration of children's perceptions and enjoyment of school-based physical activity and physical education. Journal of Physical Activity and Health, 8(5): 645-654.

Creswell JW (2014) Research design: Qualitative, quantitative and mixed methods approaches $\left(4^{\text {th }} \mathrm{ed}\right)$. London: Sage.

Department for Education. (2013a) PE programmes of study: key stages 1 and 2 national curriculum in England. Retrieved from:

https://www.gov.uk/government/uploads/system/uploads/attachment data/file/239040/P RIMARY national curriculum - Physical education.pdf 
Department for Education. (2013b) Teachers' Standards: guidance for school leaders, school staff and governing bodies. Retrieved from:

https://www.gov.uk/government/uploads/system/uploads/attachment data/file/301107/T eachers Standards.pdf

Department for Education (2017) Guidance PE and sport premium: funding allocations for 2017 to 2018. Retrieved from: https://www.gov.uk/government/publications/pe-andsport-premium-funding-allocations-for-2017-to-2018

Dyson B (2006) 3.9 Students' perspectives of physical education. Handbook of physical education, 326.

Dyson B, Cowan J, Gordon B, Powell D and Shulruf B (2017) Physical education in Aotearoa New Zealand primary schools: Teachers' perceptions and policy implications. European Physical Education Review, p.1356336X17698083.

Fairclough SJ and Stratton G (2006) A review of physical activity levels during elementary school physical education. Journal of teaching in physical education, 25(2): 240-258.

Flewitt R (2014) Interviews. In Clark, A. et al. (Eds.) Understanding research with children and young people. London: Sage.

Hollis JL, Williams AJ, Sutherland, $R$ et al. (2016) A systematic review and metaanalysis of moderate-to-vigorous physical activity levels in elementary school PE lessons. Preventive medicine, 86: 34-54.

Lonsdale C, Rosenkranz RR, Peralta LR, Bennie A, Fahey P and Lubans DR (2013) A systematic review and meta-analysis of interventions designed to increase moderate-tovigorous physical activity in school physical education lessons. Preventive Medicine, 56(2):152-161.

McClain JJ, Abraham TL, Brusseau TA, et al. (2008) Epoch length and accelerometer outputs in children: comparison to direct observation. Medicine and Science in Sports and Exercise, 40(12): 2080-2087.

McKenzie TL (2002) The use of direct observation to assess physical activity. In G. Welk (Ed.), Physical activity assessments for health-related research. Champaign, IL: Human Kinetics.

McKenzie TL (2010) Seeing is believing: observing physical activity and its contexts. Research Quarterly for Exercise and Sport, 81(2): 113-122. 
McKenzie TL (2015) 'System for Observing Fitness Instruction Time: Description and Procedures Manual' Available at: http://activelivingresearch.org/sites/default/files/SOFIT Protocols 05.01.15.pdf

McLeroy KR, Bibeau D, Steckler A, et al. (1988). An ecological perspective on health promotion programs. Health Education Quarterly, 15: 351-377.

Menter IJ, Elliot D, Hulme M, et al. (2011) A guide to practitioner research. London: Sage.

Ofsted (2013). Beyond 2012 outstanding PE for all. Retrieved from: http://www.solent.ac.uk/sport/resources/beyond-2012-report.pdf

Parker M, MacPhail A, O'Sullivan M, Chróinín DN and McEvoy E (2017) 'Drawing' conclusions: Irish primary school children's understanding of physical education and physical activity opportunities outside of school. European Physical Education Review, p.1356336X16683898.

Patton K, Parker M and Tannehill D (2015) Helping teachers help themselves: Professional development that makes a difference. NASSP Bulletin, 99(1): 26-42.

Safdie M, Cargo M, Richard $L$ and Lévesque $L$ (2014) An ecological and theoretical deconstruction of a school-based obesity prevention program in Mexico. International Journal of Behavioral Nutrition and Physical Activity, 11(1): 103.

Shenton AK (2004) Strategies for ensuring trustworthiness in qualitative research projects. Education for information, 22(2): 63-75.

Smith JA (1997) Developing theory from case studies: self-reconstruction and the transition to motherhood. In Hayes (Ed.) Doing Qualitative Analysis in Psychology. Hove: Psychology Press.

Smith JA, Flowers P and Larkin M (2009) Interpretative phenomenological analysis: Theory, method and research. London: Sage.

Tsangaridou N (2012) Educating primary teachers to teach physical education. European Physical Education Review, 18(3): 275-286.

Ward G and Griggs G (2017) Primary Physical Education: A memetic perspective. European Physical Education Review, p.1356336X16676451.

Williams MN, Grajales CAG and Kurkiewicz D (2013) Assumptions of multiple regression: correcting two misconceptions. Practical Assessment, Research \& Evaluation, 18(11): 2. 
Willig C (2001) Introducing qualitative research in psychology: Adventures in theory and method. Buckingham: University Press.

\section{Author biographies}

Emma Powell is a Senior Lecturer in Primary Education, specialising in Physical Education Pedagogy at Newman University, Birmingham, UK.

Lorayne A Woodfield is a Senior Lecturer in Physical Activity and Health, and Physical Education Pedagogy at Newman University, Birmingham, UK.

Alan M Nevill is the Research Professor in the Faculty of Education Health and Wellbeing, Wolverhampton University, UK (specialisation in biostatistics applied to health, sport and exercise sciences).

Alex J Powell is a Lecturer in Coaching Science, specialising in coach education and the development of mental toughness at Newman University, Birmingham, UK.

Tony D Myers is a Reader in Sport Psychology, specialising in quantitative and qualitative research methods in sport and exercise sciences at Newman University, Birmingham, UK. 